\title{
The Effect of High-Temperature Water Chemistry and Dissolved Zinc on the Cobalt Incorporation on Type 316 Stainless Steel Oxide
}

DOI:

10.1016/j.corsci.2018.05.041

\section{Document Version}

Accepted author manuscript

Link to publication record in Manchester Research Explorer

Citation for published version (APA):

Holdsworth, S., Scenini, F., Burke, M. G., Bertali, G., Ito, T., Wada, Y., Hosokawa, H., Ota, N., \& Nagase, M. (2018). The Effect of High-Temperature Water Chemistry and Dissolved Zinc on the Cobalt Incorporation on Type 316 Stainless Steel Oxide. Corrosion Science. https://doi.org/10.1016/j.corsci.2018.05.041

\section{Published in:}

Corrosion Science

\section{Citing this paper}

Please note that where the full-text provided on Manchester Research Explorer is the Author Accepted Manuscript or Proof version this may differ from the final Published version. If citing, it is advised that you check and use the publisher's definitive version.

\section{General rights}

Copyright and moral rights for the publications made accessible in the Research Explorer are retained by the authors and/or other copyright owners and it is a condition of accessing publications that users recognise and abide by the legal requirements associated with these rights.

\section{Takedown policy}

If you believe that this document breaches copyright please refer to the University of Manchester's Takedown Procedures [http://man.ac.uk/04Y6Bo] or contact uml.scholarlycommunications@manchester.ac.uk providing relevant details, so we can investigate your claim.

\section{OPEN ACCESS}




\title{
The Effect of High-Temperature Water Chemistry and Dissolved Zinc on the Cobalt Incorporation on Type 316 Stainless Steel Oxide.
}

\author{
Samuel Holdsworth ${ }^{1}$, Fabio Scenini ${ }^{1 *}$, M. Grace Burke ${ }^{1,}$ Giacomo Bertali $^{1}$, Tsuyoshi Ito $^{2}$, Yoichi \\ Wada $^{2}$, Hideyuki Hosokawa ${ }^{2}$, Nobuyuki Ota ${ }^{3}$, Makoto Nagase $^{3}$ \\ ${ }^{1}$ Materials Performance Centre, The University of Manchester, Oxford Road, Manchester, M13 9PL, \\ UK \\ ${ }^{2}$ Center for Technology Innovation-Energy, Hitachi, Ltd., 7-1-1 Omika-cho, Hitachi-shi, Ibarak-ken, \\ 319-1292, JAPAN \\ ${ }^{3}$ Hitachi-GE Nuclear Energy, Ltd., 3-1-1 Saiwai-cho, Hitachi-shi, Ibaraki-ken, 317-0073, JAPAN \\ *Corresponding author: f.scenini@ manchester.ac.uk
}

\begin{abstract}
Oxidation tests on Type 316 stainless steel were performed under hydrogen water chemistry and normal water chemistry for 500 hours with continuous injection of a ${ }^{59} \mathrm{Co}$ solution with and without 5 ppb of $\mathrm{Zn}$ injection. The present paper identifies the resultant oxides, analysed using analytical electron microscopy and complementary surface microstructural characterisation techniques. $\mathrm{Zn}$ injection has been shown to reduce Co incorporation in the inner oxide layer under both water chemistry conditions. The secondary effects of $\mathrm{Zn}$ injection on the oxide film growth have also been investigated and discussed.
\end{abstract}




\section{INTRODUCTION}

The major contributor to the radiation dose received by workers within nuclear power plants (NPPs) is radiation fields brought about by the highly radioactive ${ }^{60} \mathrm{Co}$. The non-active ${ }^{59} \mathrm{Co}$ cation is contained within corrosion products suspended/ dissolved in the coolant; however, boiling processes in the core can lead to deposition on the fuel cladding, upon which activation through neutron capture occurs, yielding ${ }^{60} \mathrm{Co}$ containing corrosion-related unidentified deposits, known as CRUD[1][2]. During operation, the CRUD can be released through erosion and dissolution processes from the cladding surface and deposit on reactor internals causing activity build-up [3][4][5][6][7]. Although there are continued efforts to reduce the amount of cobalt in reactor components by the replacement of cobaltchromium based Stellite ${ }^{\mathrm{TM}}$ alloys, ${ }^{60} \mathrm{Co}$ deposition still dominates the out of core radiation fields.

The consideration of the oxide growth mechanism under high-temperature aqueous conditions is fundamental to the phenomenon of activity build-up associated with ${ }^{60} \mathrm{Co}$. The mechanism proposed by J.Robertson in 1991 [8] by which a duplex oxide forms is accepted for oxide growth on stainless steels whereby the inner layer exists as a thin, dense, fine-grained $\mathrm{Cr}$ enriched spinel layer and the outer layer is coarse-grained, loosely packed Fe enriched spinel reprecipitated at the oxide-solution interface.

The inner layer forms by the process of non-selective oxidation where the formation of the expected passive $\mathrm{Cr}_{2} \mathrm{O}_{3}$ layer decreases as the oxide growth rate exceeds the Fe-dissolution rate. Therefore, the oxide growth is now limited by diffusion of elements through the oxide. The location of each alloying element in the oxide is controlled by its corresponding diffusion rate in the spinel-type oxide. This results in $\mathrm{Cr}$ remaining in the inner layer due to its strong preference to occupy octahedral sites in spinel; thus, diffusion rates through the oxide are slow. Meanwhile, the relatively faster diffusion of $\mathrm{Fe}$ and Ni through the oxide to the outer layer leads to the preferential dissolution of the steel. The outer layer forms at the oxide surface and is precipitated to relieve the supersaturation from the surrounding dissolution of metal ions [8][9][10].

Activity build-up occurs when ${ }^{60} \mathrm{Co}$ ions dissolved in the coolant are incorporated into the tetrahedral lattice sites of the spinel oxide where they replace $\mathrm{Ni}$ and $\mathrm{Fe}$ cations [3][11]. The rates of $\mathrm{Co}$ 
incorporation are, however, dominated by oxide structure and composition, which, in turn, depends on electrochemical conditions [3][12][13].

Under NWC the oxidising potential is high in the order of $+150 \mathrm{mV}$ vs. Standard Hydrogen Electrode (SHE) due to radiolysis of $\mathrm{H}_{2} \mathrm{O}$ yielding oxidising species such as $\mathrm{H}_{2} \mathrm{O}_{2}$ and $\mathrm{O}_{2}$. Resultantly, a hematite $\left(\alpha-\mathrm{Fe}_{2} \mathrm{O}_{3}\right)$ over ferrite $\left(\mathrm{MFe}_{2} \mathrm{O}_{4}\right)$ based oxide film is formed [13][14][15][16]. Since $\alpha-\mathrm{Fe}_{2} \mathrm{O}_{3}$ is not a spinel but belongs to the hexagonal crystal group, it has no lattice sites for cations like Co resulting in lower Co pick-up rates [17][18] compared to HWC. Secondly, the inner layer under NWC is composed of fine grains of $\mathrm{Ni}_{\mathrm{x}} \mathrm{Fe}_{3-\mathrm{x}} \mathrm{O}_{4}$, and Co incorporation to form $\mathrm{CoFe}_{2} \mathrm{O}_{4}$ from a thermodynamic consideration is less stable than $\mathrm{CoCr}_{2} \mathrm{O}_{4}$ formed under $\mathrm{HWC}[4][14]$. Furthermore, an inherent $\mathrm{Cr}$ enriched spinel-type inner layer fails to form due to further oxidation of $\mathrm{Cr}^{3+}$ to the soluble $\mathrm{Cr}^{6+}$ in the form of $\mathrm{HCrO}_{4}^{-}[3]$.

Conversely, under HWC, the reducing conditions and hence low oxidising potential $(-500 \mathrm{mV}$ vs SHE) results in a more spinel-based oxide [1][19]. The inner oxide composition is markedly different to NWC with a thick $\mathrm{Cr}$ enriched inner layer consistent with $\mathrm{FeCr}_{2} \mathrm{O}_{4}$ (chromite). The outer layer is composed of large octahedral crystallites of $\mathrm{Fe}_{3} \mathrm{O}_{4}$ (magnetite) [14][15][19]. The location of $\mathrm{Co}$ incorporation under $\mathrm{HWC}$ is known to be in the inner layer the formation of $\mathrm{CoCr}_{2} \mathrm{O}_{4}$ is more favourable than $\mathrm{CoFe}_{2} \mathrm{O}_{4}$ [20]. The different oxide structures and compositions are observed when switching between NWC and HWC and leads to differences in radiation fields attributed to ${ }^{60} \mathrm{Co}$.

Radiation field mitigation technologies involving the injection of soluble $\mathrm{Zn}$ species is in operation across many plants. The $\mathrm{Zn}$ stabilises the oxide and prevents the incorporation of other species, namely ${ }^{60} \mathrm{Co}$ into the oxide due to its strong preference for tetrahedral sites in the oxide [3][18][21]. Furthermore, $\mathrm{Zn}$ also has the effect of replacing the ${ }^{60} \mathrm{Co}$ previously incorporated into the oxide during standard operation. Rejected ${ }^{60} \mathrm{Co}$ in the coolant can then be removed by the Reactor Water Cleanup (RWCU) system [22].

In the present work, the oxide films formed on Type 316 SS exposed to a simulated functional hot test in a BWR coolant under both NWC and HWC with/without Zn injection are investigated by advanced electron microscopy techniques. The amount of ${ }^{59} \mathrm{Co}$ and $\mathrm{Zn}$ incorporation and their localisation 
within the oxide has been analysed using surface analytical and morphological analysis, analytical electron microscopy combined with energy dispersive x-ray spectroscopy (EDXS) analysis and Laser Raman spectroscopy (LRS). ${ }^{59} \mathrm{Co}$ was used because it is chemically identical to ${ }^{60} \mathrm{Co}$ but, being nonradioactive, facilitates the safe handling of the coupons and the subsequent microstructural characterisation. The present research is relevant to a hot functional test with an aqueous $\mathrm{Zn}$ injection, and it was not aimed at simulating post-fuel cycle Zn injection operations to reduce the shutdown dose rates attributed to ${ }^{60} \mathrm{Co}$. 


\section{EXPERIMENTAL DETAILS}

\section{Sample Preparation and Oxidation}

The material used in this study was type 316L SS with a composition depicted in Table 1 . The samples $(\mathrm{L}=15 \mathrm{~mm} \times \mathrm{W}=8 \mathrm{~mm} \times \mathrm{T}=1.5 \mathrm{~mm})$ were mechanically polished with 600 -grit silicon carbide abrasive paper wetted with deionised water, then cleaned in an ultrasonic ethanol bath to remove surface contaminants.

The samples were subsequently exposed to simulated BWR operating conditions using a recirculating flow loop autoclave with wetted components was constructed of Type 316 SS, (equivalent to the material of the tested samples). The design of the loop consisted of two separate flow circuits both being supplied by a 200-litre feed tank. The first loop was the high temperature and pressure loop and the second was a low-pressure loop containing the demineralised (nuclear grade mixed bed ion exchange resins) and water chemistry analysis apparatus (dissolved oxygen and hydrogen sensors, conductivity and $\mathrm{pH}$ sensors). The feed tank water chemistry was controlled by bubbling $\mathrm{H}_{2}, \mathrm{O}_{2}$ and $\mathrm{N}_{2}$ to the desired levels of the test (Table 2). The high-temperature flow loop was pre-oxidised for 500 hours under test-equivalent conditions prior to oxidation of the samples.

Metal ion and hydrogen peroxide solutions were injected continuously at specific concentrations into the high temperature and pressure loop using two high-pressure liquid chromatography (HPLC) pumps. The metal ion and hydrogen peroxide solutions were stored in external PTFE storage tanks.

The metal ion concentrations in the high pressure and temperature circuit were monitored using Inductively Coupled Mass Spectrometry (ICP-MS) to ensure that the experimental conditions were within $0.5 \mathrm{ppb}$ of the nominal target. The exposure time for each test was 500 hours, which is considered to be adequate for the oxide to reach a steady-state [23].

\section{Microstructural Characterisation}

The oxide film generated under each water chemistry condition (Table 2) was investigated at the macro and microscopic scale using various techniques, including SEM, LRS, FIB and AEM. 
The morphological oxide analysis was performed on a Zeiss Sigma FEG-SEM equipped with an Oxford Instruments X-Max 150 Silicon Drift Detector (SDD) for EDXS and an AZTEC analysis system. Compositional information on the oxide was obtained via SEM-EDX analysis of discrete spot analyses and EDX spectrum imaging. Digital image analysis was performed to generate oxide morphology data. The Raman microscope used was a Renishaw system 1000 with a laser illumination of $512 \mathrm{~nm}$ for surface oxide phase identification. The laser beam was focused on the sample by the objective $\mathrm{x} 50$ lens. The laser power reaching the sample surface was $1.17 \mathrm{~mW}$ (at $50 \%$ laser power). The typical acquisition time was $60 \mathrm{~s}$, and three scans within the shift range of 100-1500 $\mathrm{cm}^{-1}$ were taken at each site.

The nanometre-scale analysis was performed by preparing electron transparent cross-section samples from the oxidised samples using an FEI Helios NanoLab ${ }^{\mathrm{TM}} 660$ DualBeam focussed ion beam (FIB) microscope. A protective layer of $\mathrm{Pt}(\geq \mathrm{two} \mu \mathrm{m})$ was first deposited on the specified region of interest and the near-surface regions either side of the Pt layer $\left(20 \times 15 \mu \mathrm{m}^{2}\right)$ micro-machined to yield a thin section. An in situ micromanipulator with a Pt tip was then used to extract the thin section, and it was subsequently thinned to electron transparency for AEM. The FIB sample was side mounted on the top of the $\mathrm{Cu}$ grid to reduce shadowing from the grid itself, and a low background holder was used in order to reduce spurious X-rays from the holder.

The thin cross-section sections were imaged and analysed using an FEI Talos F200X FEG Analytical TEM with 4 SDDs operating at $200 \mathrm{kV}$. Data analyses were performed using Gatan Digital Micrograph $^{\mathrm{TM}}$ and Bruker Esprit ${ }^{\mathrm{TM}}$ software. Inner oxide layer thickness measurements were completed at $300 \mathrm{~nm}$ intervals across the diameter of the thin sections using digital image analysis.

For brevity only one example from each water chemistry condition has been shown; however, the results presented in this work are based on four electron-transparent FIB specimens that had been extracted from each water chemistry condition sample, and subsequently characterized using TEM and STEM-EDX analysis. The FIB specimen was randomly selected from different regions on the samples, and the oxide thickness was measured by TEM at $300 \mathrm{~nm}$ intervals along each $15 \mu \mathrm{m}$-wide specimen; $\sim 200$ oxide thickness data points were obtained for each sample tested in a specific water chemistry. 


\section{RESULTS}

\section{Oxide Characterisation}

\section{HWC - No Zinc}

Figure 1 (a) shows a secondary electron (SE) image of the oxide generated under HWC conditions after a 500-hour exposure. The outer layer crystallites, octahedral in shape, were distributed over the oxide surface but did not wholly coat the specimen.

Further analysis was performed on the FIB-produced cross-section samples using analytical TEM and selected area electron diffraction (SAD) for oxide phase identification and elemental distributions (Figure 2 and $3(\mathrm{a}-\mathrm{d})$ ) through the thickness of the layer. SAD combined with STEM-EDX analysis confirms that the outer layer oxide was coarse single crystals of non-stoichiometric $\mathrm{NiFe}_{2} \mathrm{O}_{4}$. The inner layer SAD pattern showed continuous polycrystalline rings with the largest d-spacing rings indexed as iron chromite $\mathrm{FeCr}_{2} \mathrm{O}_{4}$ with the cubic spinel structure. The underlying type 316 austenitic stainless steel metal surface had been ground with 600 grit $\mathrm{SiC}$ paper prior to oxidation, and the near-surface deformed structure induced by grinding can be observed underneath the crystallites (Figure 1 (a)).

The STEM-HAADF image and corresponding elemental maps extracted from the STEM-EDX spectrum image dataset of the oxide and discrete spot analyses indicate enrichment of metallic $\mathrm{Ni}$ at the inner oxide/metal interface. The inner layer was a continuous $\mathrm{Cr}$ enriched layer $\sim 210 \mathrm{~nm}$ (standard deviation $=55$ ) in thickness. The outer layer crystallites were non-stoichiometric $\mathrm{NiFe}_{2} \mathrm{O}_{4}$ crystallites, which was also consistent with electron diffraction data. Given the nature of this analysis,

STEM-EDX spectrum image datasets and the extracted elemental maps are unsuitable for quantitative analysis of elements close to the background level as it is the current case for Co. For this specific reason, discrete STEM-EDX spot analyses with livetimes of $\sim 300$ seconds were used to increase the X-ray counts (and peak-to-background ratios) in the acquired spectra to generate statistically meaningful results.

The spot analyses were obtained through the thickness of the inner oxide layer for compositional data of the inner layer. The results showed a Co concentration gradient within the spinel-based inner layer 
(plotted in Figure 3 (d)). The inner/outer oxide layer boundary showed the highest concentration of Co at 1.7 wt. \%, which decreased to $0.5 \mathrm{wt}$ \% at a depth of $90 \mathrm{~nm}$ into the inner layer. At depths $>90 \mathrm{~nm}$ the Co concentration remained at a constant minimum.

The actual Co concentration in the alloy used was $0.14 \mathrm{wt}$. \% however, STEM-EDX microanalysis and quantification using the Cliff-Lorimer technique with theoretical k-factors indicated that the matrix Co concentration was $\sim 0.5$ wt. $\%$. This high value was attributed to an overestimation of Co K $\alpha$ peak due to its overlap with the Fe $\mathrm{k} \beta$. It was noted, however, that there was no correlation between the $\mathrm{Fe}$ and $\mathrm{Co}$ concentrations as a function of thickness within the inner oxide layer. On this basis, it is believed that the relative Co analysis within the oxide for comparison purposes is qualitatively correct.

Raman spectra of the HWC oxidised coupon (Figure 6 (left) black profile) shows the presence of four major peaks at $319,472,552$ and $689 \mathrm{~cm}^{-1}$. The phonon peak wavenumbers at 319 and $472 \mathrm{~cm}^{-1}$ index as the general spinel-type phase while the peaks at 552 and $689 \mathrm{~cm}^{-1}$ represent peaks relating to Iron chromite [7][17][24][25][26][27]. Therefore, the results of the LRS corroborate with the SAD and EDX results.

\section{HWC - 5 ppb Zinc}

The SE image in Figure 1 (b) represents the oxide generated after 500 hours exposure under HWC with a $5 \mathrm{ppb}$ injection of $\mathrm{Zn}$. The average crystallite size was considerably finer (average diameter $0.35 \mu \mathrm{m})$, and the surface coverage of octahedral outer layer crystallites was greater compared to the non-Zn treated samples.

The STEM-HAADF image and corresponding STEM-EDX elemental maps of the oxide (Figure 4) and discrete spot analysis results (Figure 5 (d) indicates a continuous $\mathrm{Zn}$ enrichment at the inner/outer oxide interface. The $\mathrm{Zn}$ enrichment was most significant (10 wt. \%) at the inner oxide/environment interface were the $\mathrm{Zn}$-dosed water was present. The enrichment follows a negative concentration gradient through the thickness of the inner layer oxide resulting in $\mathrm{Zn}$ concentrations $<0.2$ wt. $\% 180$ nm into the inner oxide. The SAD pattern combined with the STEM-EDX data confirmed that outer 
layer crystallites were again non- stoichiometric $\mathrm{NiFe}_{2} \mathrm{O}_{4}$ (Figure 5 (b)) and the inner layer was a very fine-grained $\mathrm{ZnCr}_{2} \mathrm{O}_{4}$ (Figure 5 (c)). The through-thickness Co concentration remained low throughout the inner layer at approximately $0.5 \mathrm{wt} . \%$. The measured thickness of the inner oxide was measured as $\sim 185 \mathrm{~nm}$ (standard deviation $=56)$.

Raman spectra for the HWC +5 ppb Zn injection oxidised coupon (Figure 6 (left) red profile) shows the presence of 4 major peaks at 319, 462, 547 and $676 \mathrm{~cm}^{-1}$. Similar to the HWC test, the peaks at 319 and $462 \mathrm{~cm}^{-1}$ index as the general spinel-type phase; however, the peaks at 547 and $676 \mathrm{~cm}^{-1}$ indicate the presence of a slightly lower $\mathrm{Cr}$-content chromite which was potentially caused by the incorporation of Zn.

\section{NWC - No Zinc}

The oxide formed under the oxidising conditions of NWC can be seen in Figure 1 (c). The oxide was dissimilar to that of HWC in that the morphology of the outer layer crystallites were non-octahedral but random polyhedral suggesting a different (non-spinel) crystal structure. The outer layer was densely packed, encompassing the underlying surface of the inner oxide and substrate.

Figure 7 is the STEM-HAADF image and corresponding STEM-EDX elemental maps for the NWC sample. They show a thin $\mathrm{Cr}$ enriched layer (blue), and an inner layer higher in $\mathrm{Ni}$ (green) compared to the HWC oxidised sample suggesting the inner layer was not $\mathrm{Cr}$ enriched spinel. The outer layer crystallites were $\mathrm{Fe}$ and $\mathrm{O}$ enriched but contained small amounts of $\mathrm{Cr}$ located towards the outer edges of the crystallites. The STEM-EDX and SAD analyses (Figure 7 and Figure 8 (b)) confirmed the presence of an $\alpha-\mathrm{Me}_{2} \mathrm{O}_{3}$ (Me: $\mathrm{Fe}, \mathrm{Cr}$ and $[\mathrm{Cr}]<<[\mathrm{Fe}]$ (haematite) outer layer and a polycrystalline $\mathrm{NiFe}_{2} \mathrm{O}_{4}$ inner layer whose thickness was approximately $\sim 195 \mathrm{~nm}$ (standard deviation $\left.=58\right)$.

Within Figure 8 (a) oxide porosity has been identified (red arrow) and was distinguishable as darkly imaging regions on the HAADF-STEM image on the NWC with/ without Zn injection samples. The porosity was located in the near-surface region of the inner oxide.

The Co concentration through the thickness of the oxide was determined through discrete STEM-EDX spot analyses. ${ }^{59}$ Co concentrations up to $\sim 1.6$ wt. $\%$ were measured at the interface between the outer and inner layer, which then decreased towards the inner layer/steel interface. 
Raman spectra for the NWC oxidised coupon (Figure 6 (b) black profile) shows the presence of 9 major peaks. The wavenumbers at 226, 243, 293, 410, 497, 611, 664 and $1322 \mathrm{~cm}^{-1}$ all refer to haematite. However, the peak at $698 \mathrm{~cm}^{-1}$ is characteristic of $\mathrm{NiFe}_{2} \mathrm{O}_{4}$.

\section{NWC - 5 ppb Zinc}

SE imaging of oxide formed under NWC with a $5 \mathrm{ppb}$ injection of $\mathrm{Zn}$ showed that outer layer crystallites exhibited a similar morphology to the oxides in non-Zn dosed NWC test; however, crystallite size was reduced by a factor of $\sim 1.5$ when compared to the NWC test.

Figure 9 is the STEM-HAADF image and corresponding STEM-EDX elemental maps for the Zndosed NWC sample. The $\mathrm{Zn}$ image shows a diffuse localisation of $\mathrm{Zn}$ to the inner layer of the oxide. STEM-EDX discrete spot analyses through the thickness of the oxide were performed to assess the $\mathrm{Zn}$ concentration (Figure 10 (d)) and confirmed that the $\mathrm{Zn}$ was isolated only to the inner layer oxide and varied up to 5.3 wt. \%. The Co concentration through the thickness of the oxide followed the same trend but was enriched up to 1.2 wt. $\%$.

STEM-EDX and SAD characterisation of the inner and outer layer oxides (Figure 10 (a-d)) revealed the presence of an $\alpha-\mathrm{Me}_{2} \mathrm{O}_{3}$ ( $\mathrm{Me}: \mathrm{Fe}, \mathrm{Cr}$ and $[\mathrm{Cr}] \ll[\mathrm{Fe}]$ based outer layer and polycrystalline $\mathrm{NiFe}_{2} \mathrm{O}_{4}$ about $\sim 155 \mathrm{~nm}$ (standard deviation $=37$ ) thick.

The Raman spectra for the Zn dosed NWC test (Figure 6) matched the peaks for the spectra obtained from the non-Zn dosed NWC tests, which were indexed as haematite and $\mathrm{NiFe}_{2} \mathrm{O}_{4}$ spinel.

\section{DISCUSSION}

\section{Co and Zn Incorporation under HWC}

Detailed characterisation of the oxides generated under HWC conditions with and without Zn injection has been compared, and the dual benefits of $\mathrm{Zn}$ injection have been investigated.

Significantly, the effect of Zn injection under HWC conditions can be seen from the STEM-EDX analyses through the reduction of Co pick-up in the oxide. The non- $\mathrm{Zn}$ treated sample contained $\sim 1.7$ wt. $\%$ Co at the inner oxide-coolant boundary which is markedly higher than the $\sim 0.5$ wt. $\%$ measured for the $\mathrm{Zn}$-treated sample. Ohashi and Ito [19] also observed a reduction in Co by a factor of 3 with $\mathrm{Zn}$ 
injection in the coolant. The mechanism of $\mathrm{Zn}$ uptake is proposed to be mechanistically similar to that for Co uptake. Nevertheless, $\mathrm{Zn}$ has a preference for tetrahedral spinel sites higher to that of Co and can replace it. The results of this present investigation are consistent with $\mathrm{Zn}$ ions occupying a larger proportion of the tetrahedral sites through the sorption and replacement of cations of lower site preference energy, namely Co among others.

The crystal structure and phase have also been considered to explain the localisation of $\mathrm{Zn}$ to the inner layer of the oxide. The polycrystalline inner layer oxide phase under HWC and HWC with Zn were identified via the combination of STEM-EDX microanalysis and SAD as $\mathrm{FeCr}_{2} \mathrm{O}_{4}$ and $\mathrm{ZnCr}_{2} \mathrm{O}_{4}$ with the regular spinel structure (Figure 3a and Figure 6a). Furthermore, the outer layer crystallites were identified as non-stoichiometric $\mathrm{NiFe}_{2} \mathrm{O}_{4}$, which is consistent with the octahedral morphology shown in Figure $1(\mathrm{a}$ and $\mathrm{b})$. The Raman data further supplements the results from STEM-EDX analyses and SAD pattern analyses with peak analysis yielding the presence of spinel and iron chromates.

The free energy of formation of $\mathrm{Zn}$-containing inverse/ normal spinels is higher than that for $\mathrm{Zn}$ replacement of divalent cations such as $\mathrm{Co}, \mathrm{Fe}$ and $\mathrm{Ni}$ (Table 3). Thus, the formation of $\mathrm{ZnCr}_{2} \mathrm{O}_{4}$ is thermodynamically more favourable than that of $\mathrm{ZnFe}_{2} \mathrm{O}_{4}$, which can be seen in Figure 5 (d) where $\mathrm{Zn}$ is predominantly localised to the inner layer which was also found by Ziemniak et al. [28].

The oxide formed under HWC with a $5 \mathrm{ppb} \mathrm{Zn}$ injection showed that the $\mathrm{Zn}$ exhibits a concentration gradient of 10 wt. $\%$ at the inner oxide/coolant interface, which decreases moving through the thickness of the oxide (Figure 2 and Figure 3 d). The proposed mechanism for the results of this study is that during early stages of oxidation metal dissolution rates and oxide growth rates are high (logarithmic rate law applies). The spinel-type oxide is therefore rapidly forming at the water/oxide interface resulting in the presence of a large amount of available tetrahedral sites which, when exposed to the $\mathrm{Zn}$-dosed water, rapidly incorporate $\mathrm{Zn}$ cations due to its strong competitiveness for replacing the less thermodynamically favourable divalent cations (mainly $\mathrm{Fe}^{2+}$ ). The Zn-saturated spinel remains at the oxide/water interface during oxide growth with $\mathrm{Zn}$ cations diffusing through the oxide (as well as along grain boundaries and micropores) to give the concentration gradient attained in the present work. Secondly, the continuous $\mathrm{Zn}$ layer then acts as a stable barrier to Co cations in the water, thus 
preventing Co uptake into the oxide. The stoichiometry of the $\mathrm{Zn}$ containing chromite inner oxide depends on the dissolved concentration within the aqueous phase.

Furthermore, the effects of $\mathrm{Zn}$ injection on the oxide thickness was seen as the reduction in inner oxide layer thickness. The Zn-treated samples had an inner layer thickness of $\sim 185 \mathrm{~nm}$ compared to $\sim 210$ $\mathrm{nm}$ for the non-Zn-treated sample. The addition of $\mathrm{Zn}$ to tetrahedral sites within the oxide causes a reduction of lattice parameter $\left(\mathrm{FeCr}_{2} \mathrm{O}_{4} \quad a=8.379 \AA\right.$ and $\mathrm{ZnCr}_{2} \mathrm{O}_{4} \quad a=8.328 \AA$ ), increasing the resistance to diffusion (reduction in both electronic and ionic mobility) through the oxide grains. Hence, the cation release rates are reduced, and a thinner oxide layer with higher protective properties is produced [28][29]. The results presented in this work show that $\mathrm{Zn}$ reduces the inner oxide layer thickness and these results are consistent with previous work [28][30].

Previous work by Ziemniak et al. [28] reported a third oxide phase that formed during Zn injection due to the miscibility gap in the $\left(\mathrm{Fe}_{1-n} \mathrm{Zn}_{\mathrm{n}}\right) \mathrm{Fe}_{2} \mathrm{O}_{4}$ binary phase diagram [28]. Based on their XPS and XRD data, they interpreted this phase as consisting of a layer of $\sim 20 \mathrm{~nm}$ ferrite crystallites with the composition $(\mathrm{Fe}, \mathrm{Ni})_{1-2} \mathrm{Zn}_{\mathrm{n}} \mathrm{Fe}_{2} \mathrm{On}=0.05$ (equivalent to a mass percent of 1.35 wt. \% $\mathrm{Zn}$ ). This "sublayer" grain size was comparable to the inner layer grain size that acts as an enhanced barrier to retard ingress of water/oxidants. The presence of the fine-grained (low $\mathrm{Zn}$ concentration) ferrite layer was not present under the conditions used in the present research. This is most likely due to significant differences in the experimental conditions as Ziemniak et al. [28] used significantly higher concentrations (30 ppb) of injected $\mathrm{Zn}$ coupled with a longer exposure times (>1000 hours).

The absence of an outer $\mathrm{Zn}$ enriched layer that was reported in other References [21][28] could also be associated with the difference in the refresh rates of the autoclave: in the present work the autoclave was refreshed every 30 seconds, whilst Ziemniak et al. refreshed once every 100 minutes and Liu et al.[21] used a static autoclave system. Since the outer layer forms by a re-precipitation of $\mathrm{Ni}$ and Fe ions that are supersaturated at the solution-oxide interface, the refresh rate of the autoclave would be expected to have a significant effect on the nature of the outer oxide layer. 


\section{Co and Zn Incorporation under NWC}

The high oxidising potential under NWC conditions generated a distinctly dissimilar oxide to that of the reducing conditions of HWC with detailed characterisation highlighting the effects of $\mathrm{Zn}$ injections on the Co uptake and the oxide morphology under NWC.

The STEM-EDX data suggest that under NWC conditions there is the localisation of Co in the polycrystalline nickel ferrite inner oxide layer. The maximum Co concentration was measured to be equivalent when taking into account the errors in the EDS data. However, as evident in Figure 3 a and Figure $8 \mathrm{~d}$, Co enrichment was spread over a thicker depth in NWC, meaning that the integrated total Co pick-up was about a factor of 2 larger than under HWC conditions.

The AEM characterisation (Figure 4 and 9) revealed the behaviour of $\mathrm{Zn}$ under NWC to be different to that for HWC. The localisation of Zn did not follow a concentration gradient through the inner oxide but was dispersed throughout the inner oxide layer indicating the movement of $\mathrm{Zn}$ is not governed by diffusion through the oxide lattice itself.

Figure 10 showed the porous nature of the inner oxide under these conditions. The inner oxide layer porosity that was identified in the NWC sample plays an important role in the oxidation rate. The presence of interconnected porosity within the inner layer increases the diffusion rates of oxidant to the metal-oxide interface, resulting in increased diffusion rates and dynamic equilibrium being reached at a faster rate. Furthermore, the friability of the oxide may increase, resulting in the oxide becoming more susceptible to local hydrodynamic removal effects. Thus, the porosity may lead to increased $\mathrm{Zn}$ mobility through the oxide (facilitated by micropores) resulting in the accumulation of $\mathrm{Zn}$ throughout the inner layer.

Both the HWC and NWC tests operated with a 5 ppb Zn injection, however, the magnitude of Znenrichment was $\leq 5.7$ wt. $\%$ for the Zn-dosed NWC test compared to $\sim 10.0 \mathrm{wt}$. $\%$ of the Zn-dosed HWC test.

The results published in Reference [7] differ from the findings in the present research, which has demonstrated that $\mathrm{Zn}$ is incorporated into the inner layer under both NWC and HWC conditions when $\mathrm{Zn}$ is added to the water. This discrepancy is most likely associated with the different analytical 
techniques employed in these studies: a chemical dissolution technique was used in Ref. [7], whereas STEM-EDX microanalysis techniques with high spatial resolution were used in the present investigation

The SAD pattern analyses revealed that the outer oxide under NWC with/without $\mathrm{Zn}$ injection was haematite based and the inner layer was polycrystalline nickel ferrite (Figure 10 (c)). The formation of these phases is consistent with the oxygen partial pressure gradient across the oxide. Furthermore, under NWC a 5 ppb injection of Zn did not alter the crystal structure of the oxide, which was found in research from Inagaki et al. [31]. The inner layer was not composed of a $\mathrm{Cr}$ enriched spinel layer as the oxidising potential under NWC as the oxidising potential is capable of oxidising $\mathrm{Cr}^{3+}$ to $\mathrm{Cr}^{6+}$ in the form of the highly soluble $\mathrm{CrO}_{4}^{-2}$, thus resulting in a less protective non-Cr based $\mathrm{NiFe}_{2} \mathrm{O}_{4}$ inner layer. Furthermore, Co incorporation into the $\alpha-\mathrm{Fe}_{2} \mathrm{O}_{3}$ outer oxide does not occur as haematite is not spinel but rhombohedral; therefore, there are no tetrahedral sites for Co or $\mathrm{Zn}$ to incorporate into [17][18][28]. Zn injection under NWC was also found to decrease the inner oxide layer thickness by $25 \%$ which highlights the protective properties of $\mathrm{Zn}$ within the spinel-type oxide. 


\section{CONCLUSIONS}

Oxidation studies were performed on type 316 stainless steel under simulated BWR conditions under four different water chemistry conditions for 500 hours. The resulting surface oxides and microstructure was characterised using advanced FEG-SEM, FIB and AEM techniques and the effects Zn-injection on oxide morphology, phase and significantly the degree of Co pick up was tested:

(1) The ${ }^{59}$ Co pick-up under HWC was localised at the inner oxide/water interface up to $1.7 \mathrm{wt} \%$ with a negative concentration gradient towards the inner oxide/steel interface.

(2) $\mathrm{Zn}$ injection of $5 \mathrm{ppb}$ prevented ${ }^{59} \mathrm{Co}$ pick-up under HWC conditions and localised at the inner oxide/water interface up to $10 \mathrm{wt} . \%$ and decreased in concentration through the thickness of the inner oxide. This further suggests the mechanism of $\mathrm{Zn}$ incorporation is equivalent to that Co. Analysis of selected area electron diffraction data obtained from a $5.0 \mathrm{ppb} \mathrm{Zn}$ injection sample confirmed the presence of an inner layer of $\mathrm{ZnCr}_{2} \mathrm{O}_{4}$ which is a more stable oxide, thereby reducing corrosion rates.

(3) No discernible difference in the maximum ${ }^{59}$ Co concentration pick-up under NWC ( $\leq 1.6$ wt. $\%)$ and HWC test $\left(1.7 \%\right.$ wt. \%) was found; however, the total ${ }^{59}$ Co pick-up across the inner oxide was a factor of two larger for NWC conditions.

(4) Zn injection under HWC and NWC was effective at lowering the ${ }^{59} \mathrm{Co}$ accumulation, however, the effects of $\mathrm{Zn}$ injection at lowering the ${ }^{59} \mathrm{Co}$ content of the inner layer under NWC conditions were less pronounced. The oxide phase analysis revealed the presence of a porous $\mathrm{NiFe}_{2} \mathrm{O}_{4}$ based polycrystalline inner layer which may contribute to corrosion kinetics.

(5) The effects of Zn-injection under both HWC and NWC had the effect of reducing overall oxide thickness which based upon accepted corrosion models for stainless steels would be attributed to the reduction of cation release rates. However, the effect was more pronounced under NWC conditions as a $25 \%$ reduction in inner layer oxide thickness compared to a $13 \%$ decrease for HWC. 
It is proposed that $\mathrm{Zn}$ injection at the start of a fuel cycle would be more beneficial because the spineltype oxide that forms would saturate in $\mathrm{Zn}$, significantly reducing the ${ }^{60} \mathrm{Co}$ uptake during operation and would form a more stable and protective oxide due to the beneficial corrosion inhibition effects. 


\section{ACKNOWLEDGEMENTS}

The authors would like to thank the Hitachi Research Laboratory in Japan for their invaluable advice on oxidation experiments. Hitachi-GE provided financial support for this project. 


\section{REFERENCES}

[1] K. Ishida and D. Lister, "In Situ measurement of corrosion of type 316L stainless steel in 553 K pure water via the electrical resistance of a thin wire," J. Nucl. Sci. Technol., vol. 49, no. 11, pp. 1078-1091, 2012.

[2] J. Chen, "On the Interaction between Fuel Crud and Water Chemistry in Nuclear Power Plants,” Ski Rep. 005, no. January 2000.

[3] C. C. Lin, "A Review of Corrosion Product Transport and Radiation Field Buildup in Boiling Water Reactors," Prog. Nucl. Energy, vol. 51, no. 2, pp. 207-224, Mar. 2009.

[4] K. Ishida and D. Lister, "New Model Of Cobalt Activity Accumulation On Stainless Steel Piping Surfaces Under Boiling Water Reactor Conditions,” pp. 1-11, 2010.

[5] C. J. Wood, "Recent developments in LWR radiation field control," Prog. Nucl. Energy, vol. 19, no. 3, pp. 241-266, Jan. 1987.

[6] J. a. Sawicki, "Analyses of fuel crud and coolant-borne corrosion products in normal water chemistry BWRs," J. Nucl. Mater., vol. 419, no. 1-3, pp. 85-96, 2011.

[7] H. Hosokawa and M. Nagase, "Investigation Of Cobalt Deposition Behavior With Zinc Injection On Stainless Steel Under BWR Conditions,” J. Nucl. Sci. Technol., vol. 41, no. 6, pp. 682-689, 2004.

[8] J. Robertson, "The Mechansim Of High Temperature Aqueous Corrosion Of Stainless Steel," Corros. Sci., vol. 32, no. 4, pp. 443-465, 1991.

[9] T. Terachi, K. Fujii, and K. Arioka, "Microstructural Characterization of SCC Crack Tip and Oxide Film for SUS 316 Stainless Steel in Simulated PWR Primary Water at $320^{\circ} \mathrm{C}$," J. Nucl. Sci. Technol., vol. 42, no. 2, pp. 225-232, 2005.

[10] S. Cissé, L. Laffont, B. Tanguy, M. C. Lafont, and E. Andrieu, "Effect of surface preparation on the corrosion of austenitic stainless steel 304L in high temperature steam and simulated PWR primary water,” Corros. Sci., vol. 56, pp. 209-216, 2012. 
[11] R. M. Sellers, "The Radiation Chemistry Of Nuclear Reactor Decontaminating Reagents," Radiat. Phys. Chem., vol. 21, no. 3, pp. 295-305, Jan. 1983.

[12] D.H.Lister, "The Mechanisms of Corrosion Product Transport and Their Investigation in High Temperature Water Loops,” vol. 35, pp. 89-96, 1979.

[13] K. Ishida, Y. Wada, and M. Tachibana, "Effects of Noble Metal Deposition upon Corrosion Behavior of Structural Materials in Nuclear Power Plants , ( I ) Effect of Noble Metal Deposition with an Oxide Film on Type 304 Stainless Steel,” vol. 42, no. 9, pp. 799-808, 2005.

[14] Y.-J. Kim, "Analysis of oxide film formed on type 304 stainless steel in $288 \mathrm{C}$ water containing oxygen, hydrogen, and hydrogen peroxide," J. Name Corros. J. Vol. 55; J. Issue 1; Other Inf. DN Pap. Present. Corros. March 1996, Denver, CO (US); PBD Jan 1999, vol. 55, no. 1, p. Medium: X; Size: pp. 81-88, 1999.

[15] Y.-J. Kim, “Characterization of the Oxide Film Formed on Type 316 Stainless Steel in $288^{\circ} \mathrm{C}$ Water in Cyclic Normal and Hydrogen Water Chemistries," Corrosion, vol. 51, no. 11, pp. 849-860, 1995.

[16] T. Miyazawa et al., "Effects of Hydrogen Peroxide on Corrosion of Stainless Steel, (V) Characterization of Oxide Film with Multilateral Surface Analyses," J. Nucl. Sci. Technol., vol. 43, no. 8, pp. 884-895, 2006.

[17] K. F. McCarty and D. R. Boehme, "A Raman study of the systems Fe3-xCrxO4 and Fe2xCrxO3,” J. Solid State Chem., vol. 79, no. 1, pp. 19-27, 1989.

[18] D. H. Lister, Nuclear Corrosion Science and Engineering. Elsevier, 2012.

[19] T. Ohashi, T. Ito, H. Hosokawa, M. Nagase, and M. Aizawa, "Investigation of cobalt buildup behavior and suppression by zinc injection on stainless steel under HWC conditions using simultaneous continuous measurements of corrosion and cobalt buildup," J. Nucl. Sci. Technol., vol. 3131, no. September 2016, pp. 1-8, 2014.

[20] A. Navrotsky and O. J. Kleppa, "The thermodynamics of cation distributions in simple spinels," J. Inorg. Nucl. Chem., vol. 29, no. 11, pp. 2701-2714, 1967. 
[21] X. Liu, X. Wu, and E. H. Han, "Influence Of Zn Injection On Characteristics Of Oxide Film On 304 Stainless Steel In Borated And Lithiated High Temperature Water," Corros. Sci., vol. 53, no. 10, pp. 3337-3345, 2011.

[22] T. Saito, K. Ichikawa, H. Ishimaru, M. Aizawa, Y. Sato, and S. Morita, "Radiation exposure reduction technologies for a Japanese Advanced BWR ( Dose Rate Reduction Experience in Shika Unit 2 )," Nucl. Plant Chem. Conferance.

[23] T. Couvant, Corrosion in pressurized water reactors (PWRs). Woodhead Publishing Limited, 2013

[24] V. S. Sathyaseelan et al., "High temperature dissolution of oxide deposits formed over structural materials under PHWR and BWR chemistry conditions," Prog. Nucl. Energy, vol. 59, pp. 100-106, 2012.

[25] G. Han, Z. Lu, X. Ru, J. Chen, Q. Xiao, and Y. Tian, "Improving the oxidation resistance of 316L stainless steel in simulated pressurized water reactor primary water by electropolishing treatment," J. Nucl. Mater., vol. 467, pp. 194-204, 2015.

[26] Y. Soma, C. Kato, and M. Yamamoto, "Growth Behavior of Surface Oxide Layer on SUS316L Stainless Steel at the Early Stage of Exposure to $288^{\circ} \mathrm{C}$ Water," Mater. Trans., vol. 53, no. 1, pp. 195-200, 2012.

[27] J. H. Kim and I. S. Hwang, "Development of an in situ Raman spectroscopic system for surface oxide films on metals and alloys in high temperature water," Nucl. Eng. Des., vol. 235, no. 9, pp. 1029-1040, 2005.

[28] S. E. E. Ziemniak and M. Hanson, "Zinc Treatment Effects On Corrosion Behavior Of 304 Stainless Steel In High Temperature, Hydrogenated Water," Corros. Sci., vol. 48, no. 10, pp. 2525-2546, 2002.

[29] W. J. Marble, “An overview of zinc addition for BWR dose rate control,” pp. 1-5, 1994.

[30] I. Betova, M. Bojinov, P. Kinnunen, and T. Saario, “Zn injection in Pressurized Water Reactors - laboratory tests, field experience and modelling,” 2011. 
[31] H. Inagaki, A. Nishikawa, Y. Sugita, and T. Tsuji, "Synergy Effect of Simultaneous Zinc and Nickel Addition on Cobalt Deposition onto Stainless Steel in Oxygenated High Temperature Water,” J. Nucl. Sci. Technol., vol. 40, no. 3, pp. 143-152, 2003. 

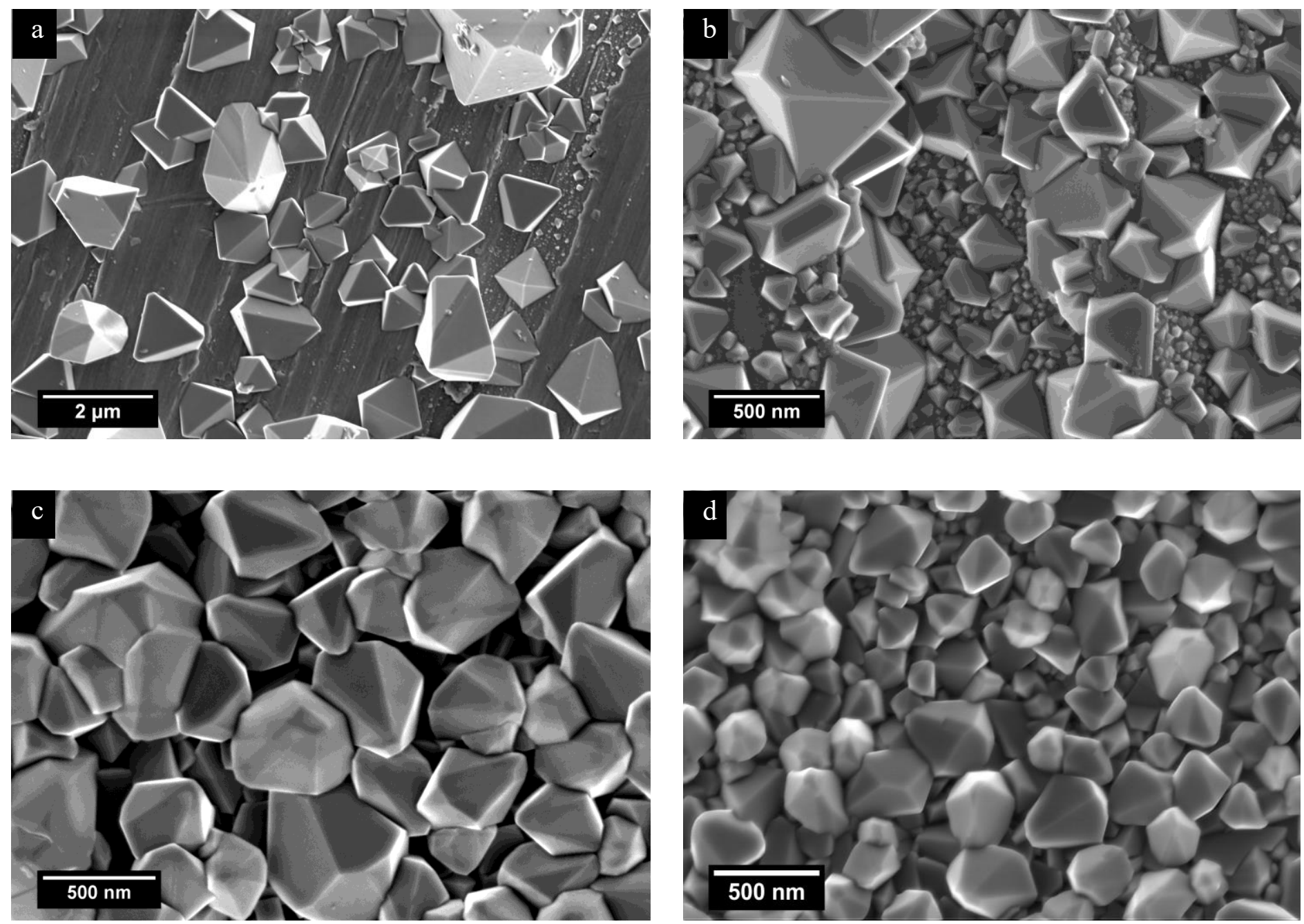

Figure 1: SE images of the typical oxide morphology formed on a surface prepared with a 600 grit surface polish under a) HWC with no Zn injection; b) HWC with a 5 ppb Zn injection; c) NWC with no Zn injection; d) NWC with a 5 ppb Zn injection. 


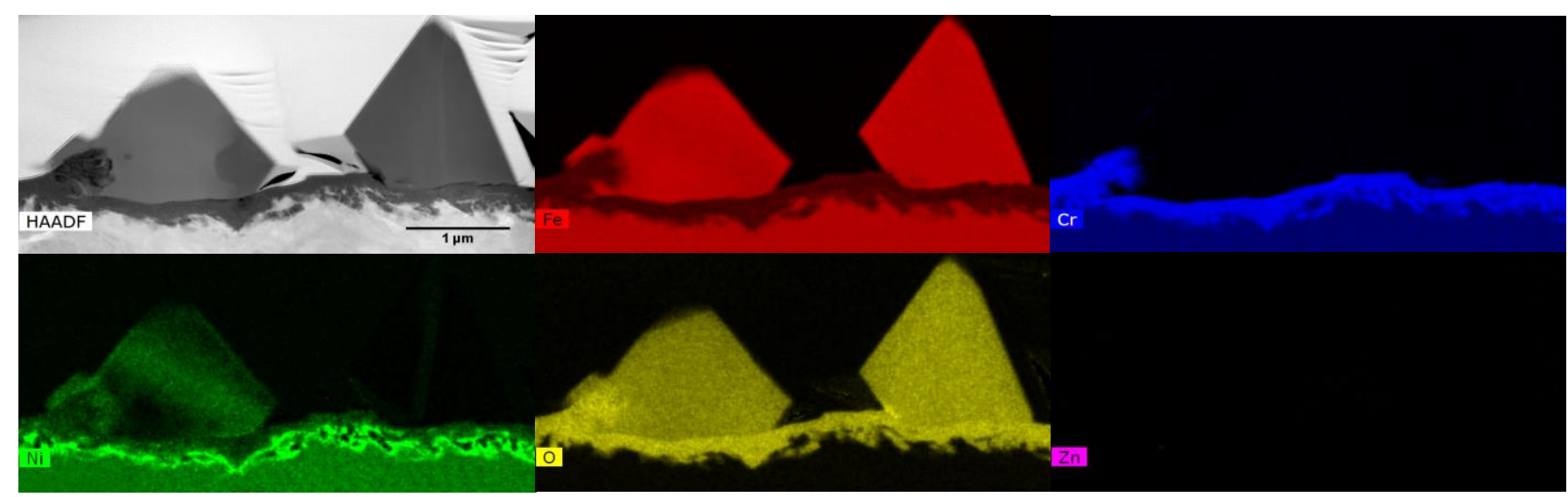

Figure 1: STEM-HAADF image and corresponding extracted compositional maps from the STEMEDX spectrum image dataset of the oxide formed under HWC showing the presence of a $\mathrm{Cr}$ enriched inner layer, a metallic Ni-rich layer beneath the inner layer oxide and the presence of nonstoichiometric nickel ferrite outer oxide (left crystallite shows Ni while the right crystallite shows no Ni). 

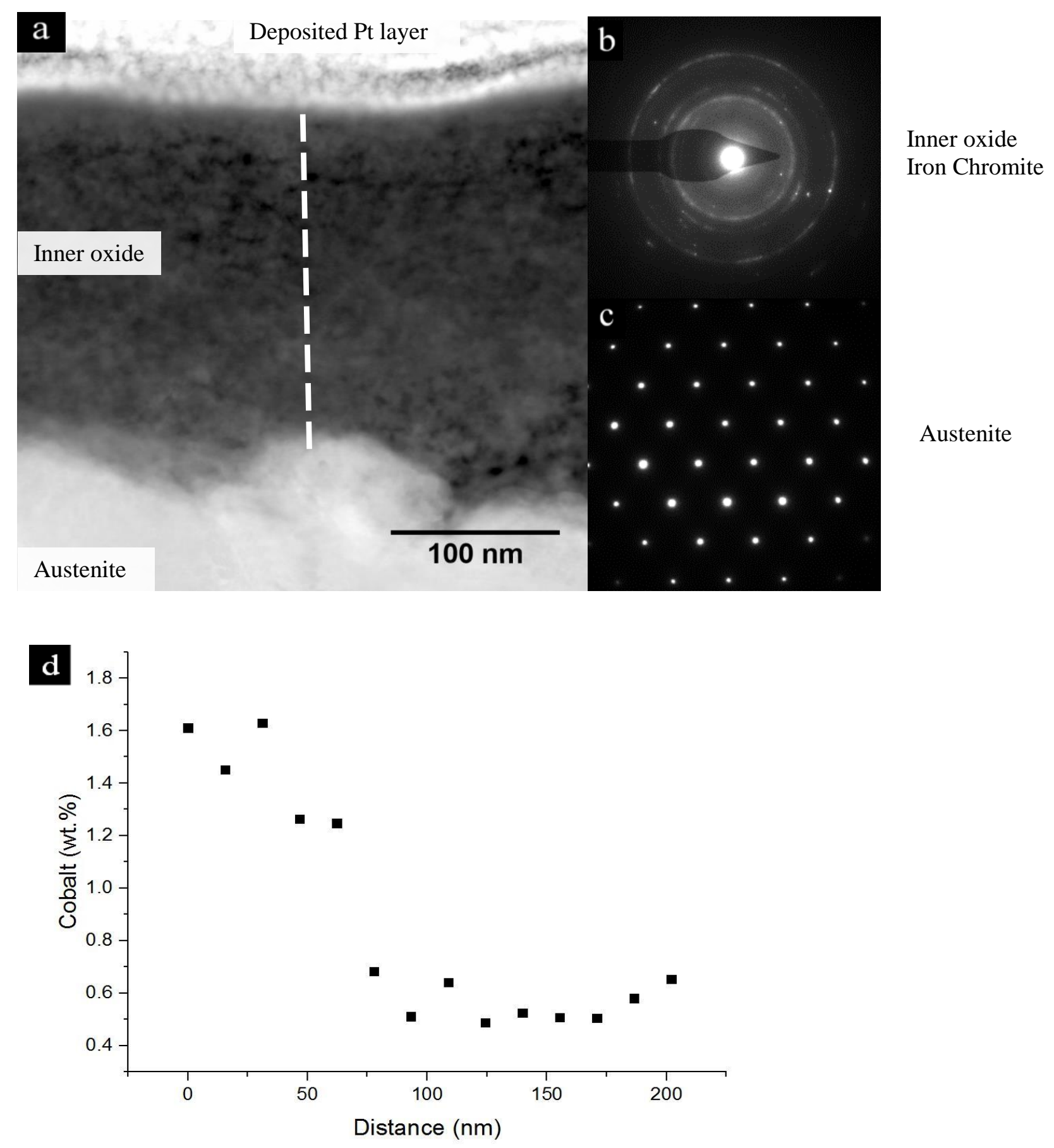

Figure 1: (a) HAADF STEM image of the inner layer oxide, discrete EDX spot scans were performed though the thickness of the inner layer represented by the white superimposed line; (b) SADP of the inner oxide; (c) SADP of the matrix; (d) Plot showing the semi-quantitative Co concentration in wt. \% through the thickness of the inner oxide. 


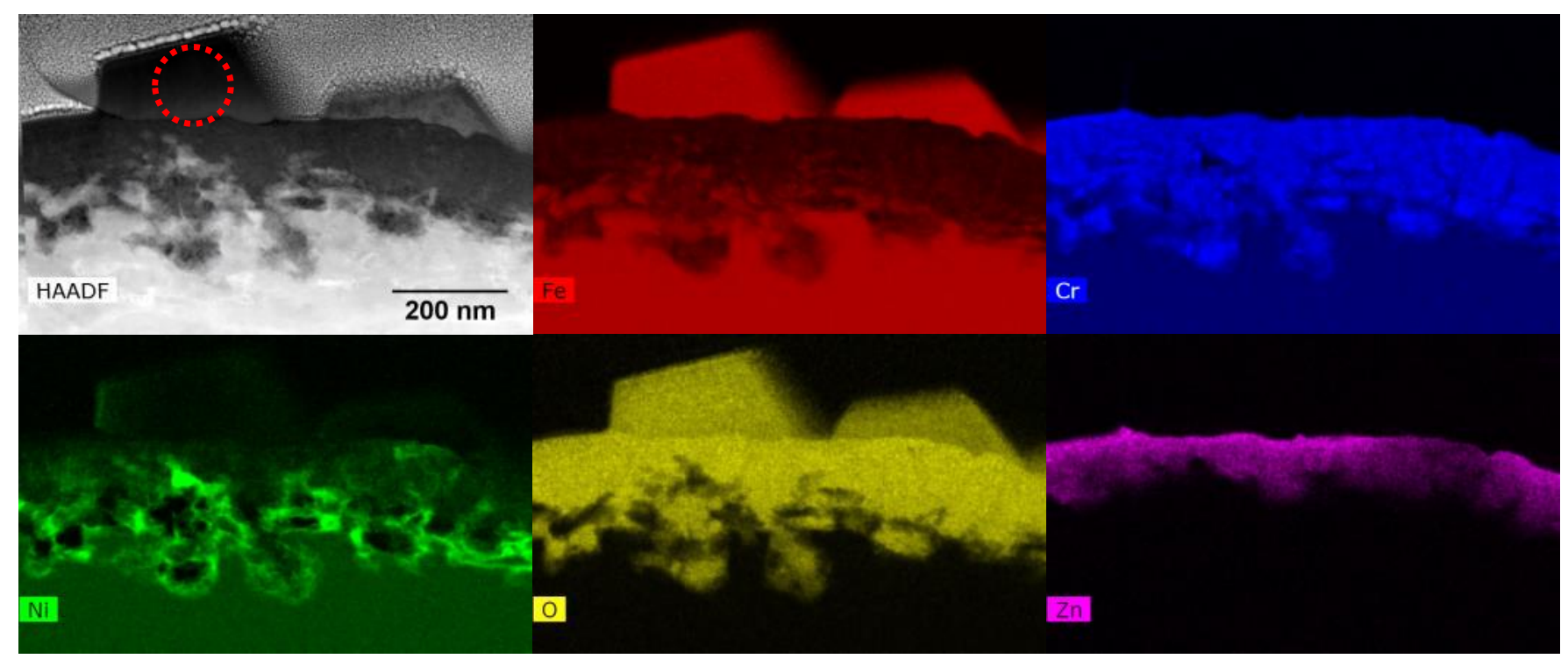

Figure 1: STEM-EDX spectrum images of the oxide formed under HWC showing the presence of a Cr enriched inner layer oxide, a metallic Ni-rich layer underneath the inner oxide/metal interface and a continuous Zn-enrichment at the top region of the inner layer. No Zn enrichment into the outer ferrite layer was detected. Red dotted circle indicates the region of SADP analysis (shown in Figure 5). 


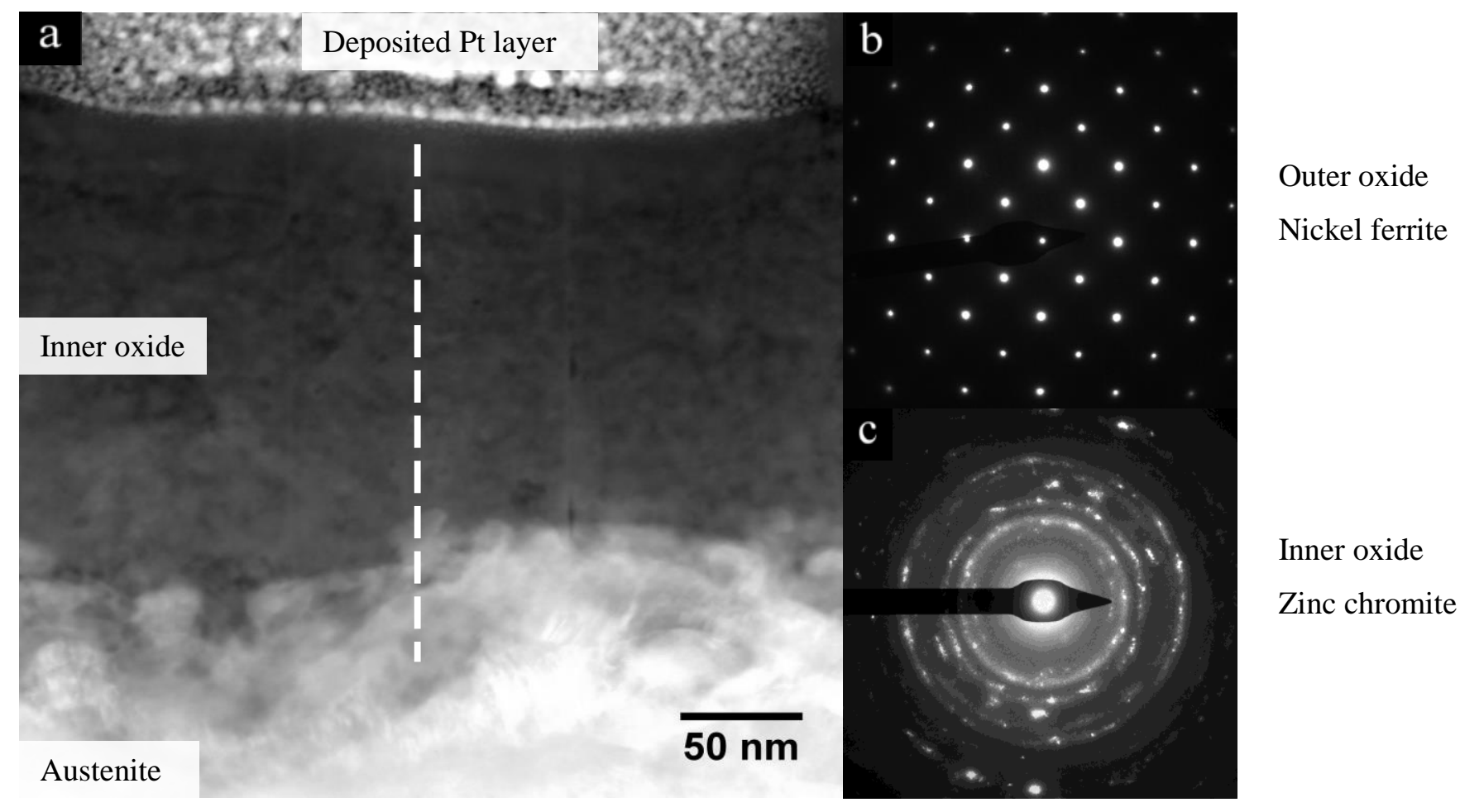

d

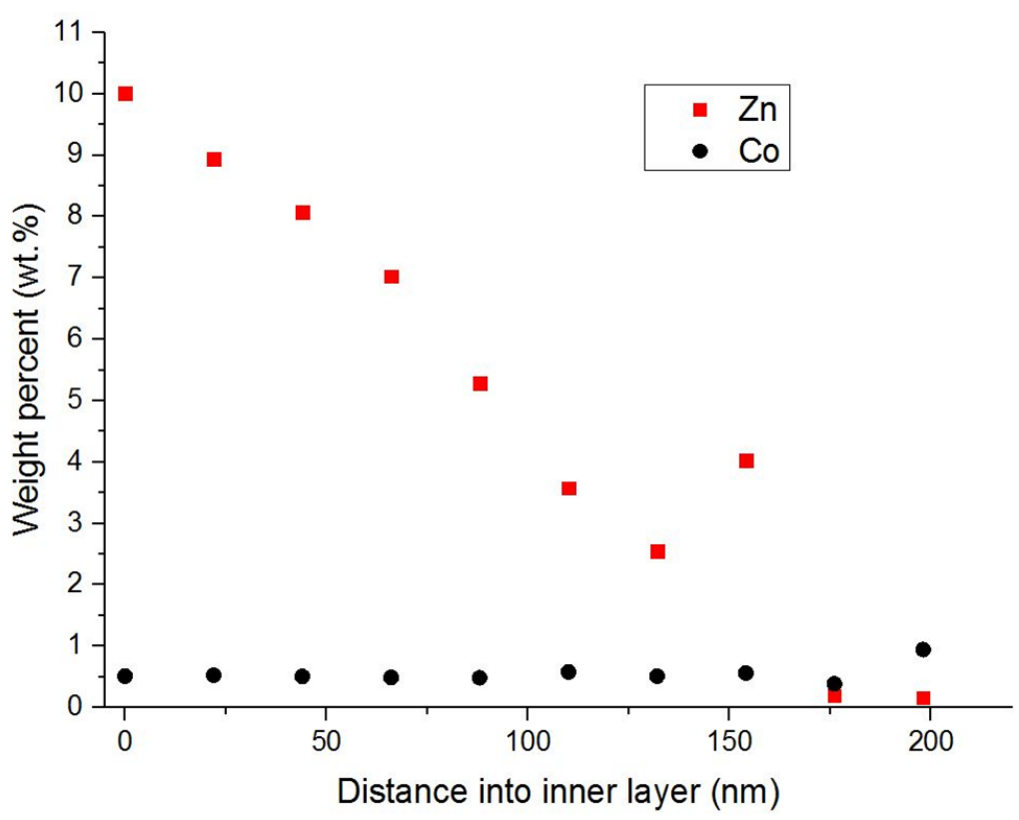

Figure 1: (a) HAADF-STEM image of the inner layer oxide on the oxide formed under HWC with Zn injection. The superimposed line representing the locations of the discrete EDX spot analysis; b) SADP of the outer layer crystallite indicated in Figure 4 (c) SADP of the inner oxide layer; (d) Plot showing the semi-quantitative $\mathrm{Co}$ and $\mathrm{Zn}$ concentration in wt. through the thickness of the inner layer oxide. 

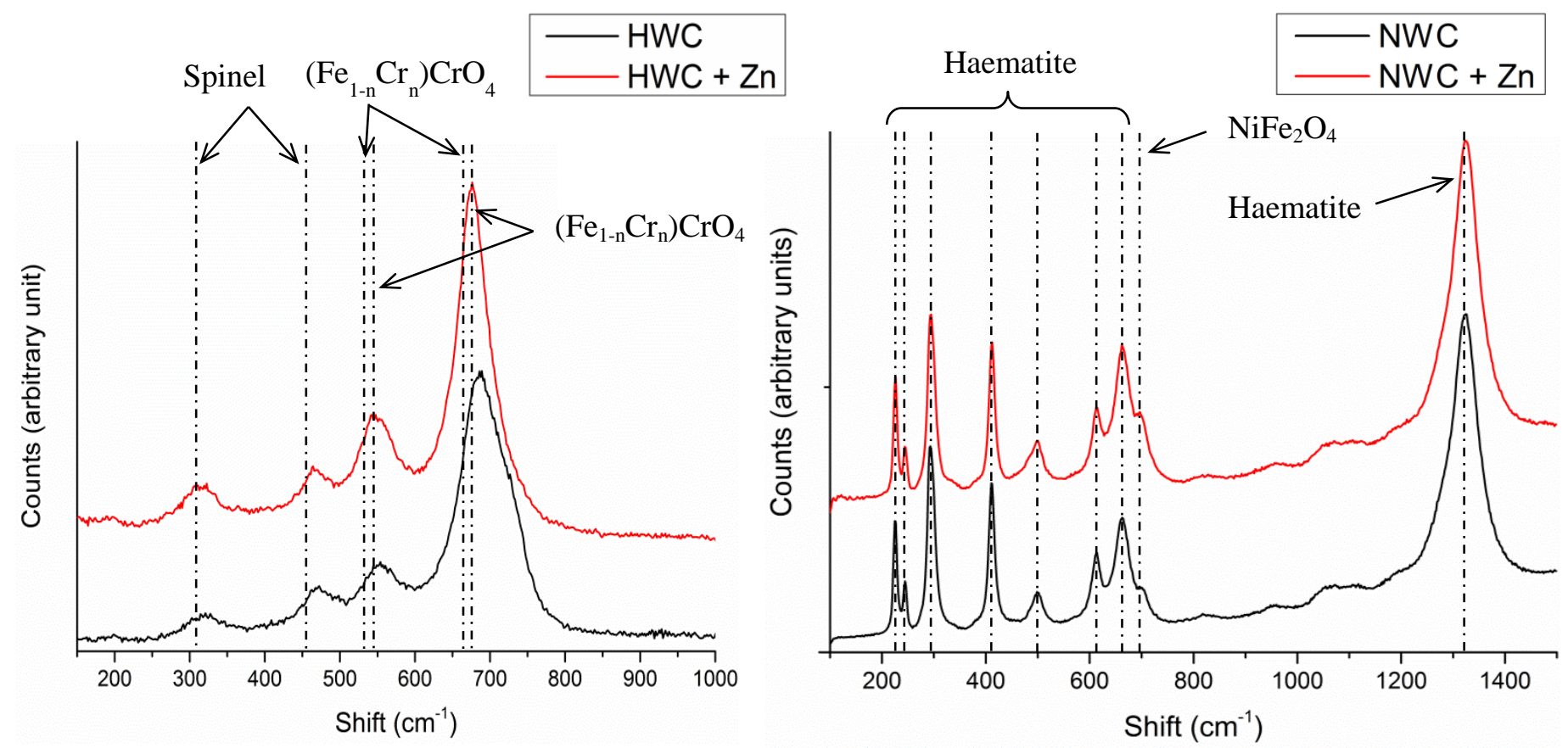

Figure 1: Combined RAMAN spectra for the HWC and NWC tests with and without a continuous 5 ppb Zn injection. 



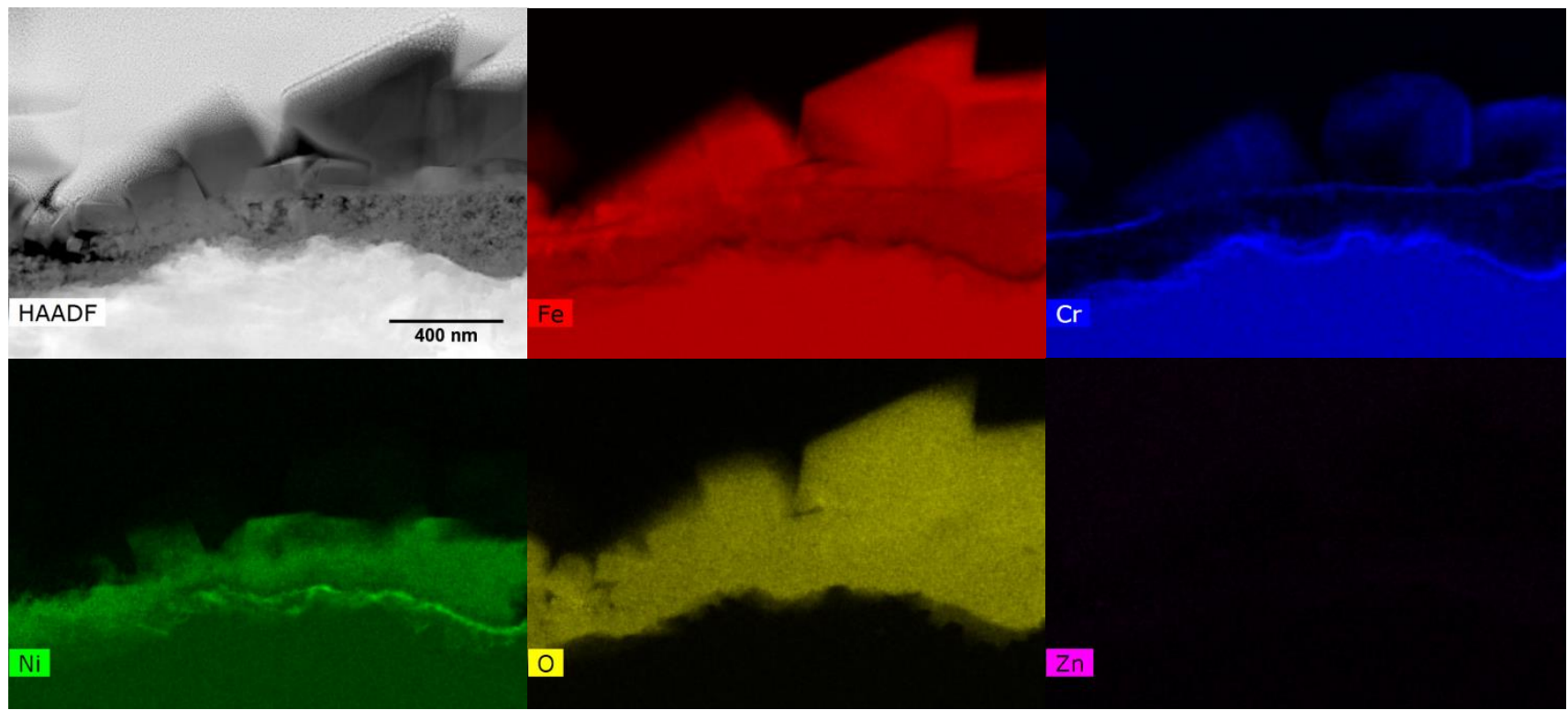

Figure 1: STEM-EDX spectrum images of the oxide formed under NWC showing the presence of a thin $\mathrm{Cr}$ enriched layer, a non-stoichiometric $\mathrm{NiFe}_{2} \mathrm{O}_{4}$ based inner layer and an outer layer which is non-octahedral and contains no Ni suggesting a haematite based outer layer. 


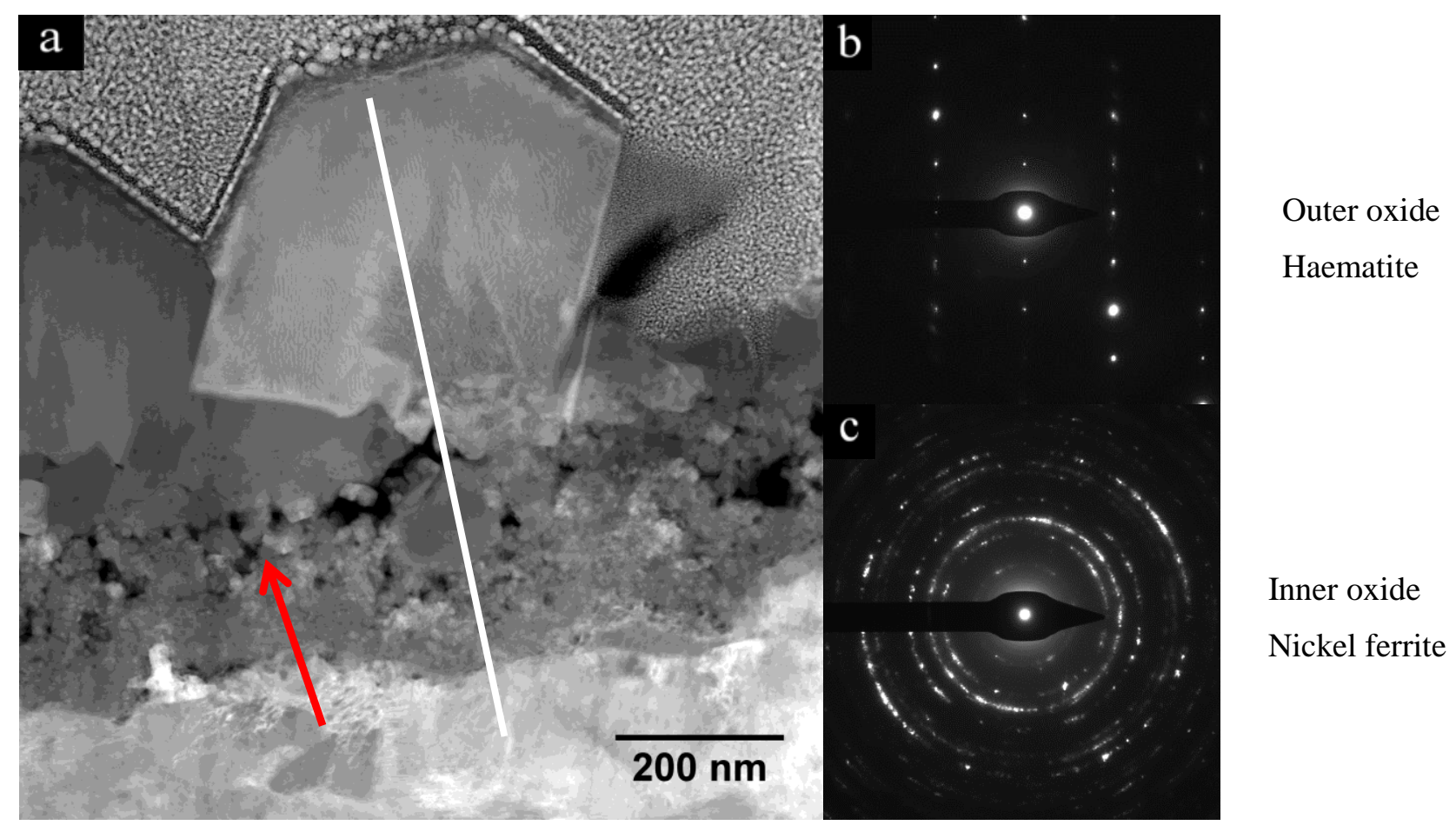

d

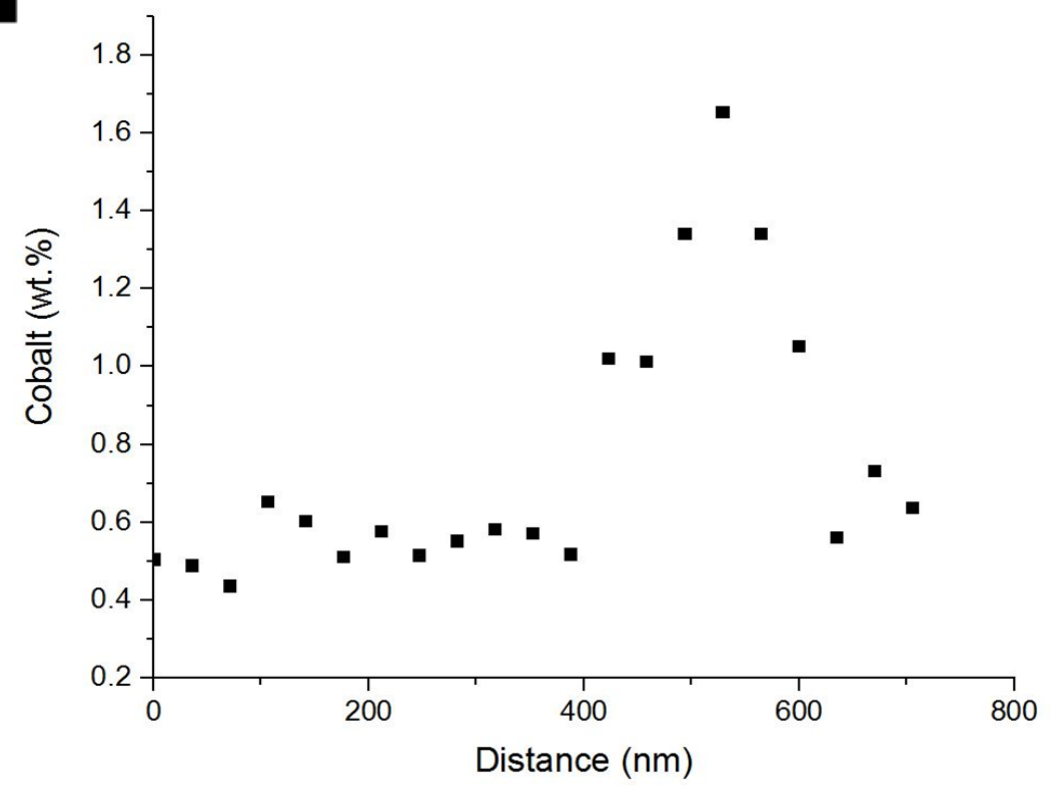

Figure 1: (a) HAADF-STEM image of the outer and inner layer oxide with the superimposed line representing the locations of the discrete EDX spot analysis; (b) SADP of the outer oxide; (c) SADP of the inner oxide (d) Plot showing the semi-quantitative Co concentration in wt. through the thickness of the oxide. 


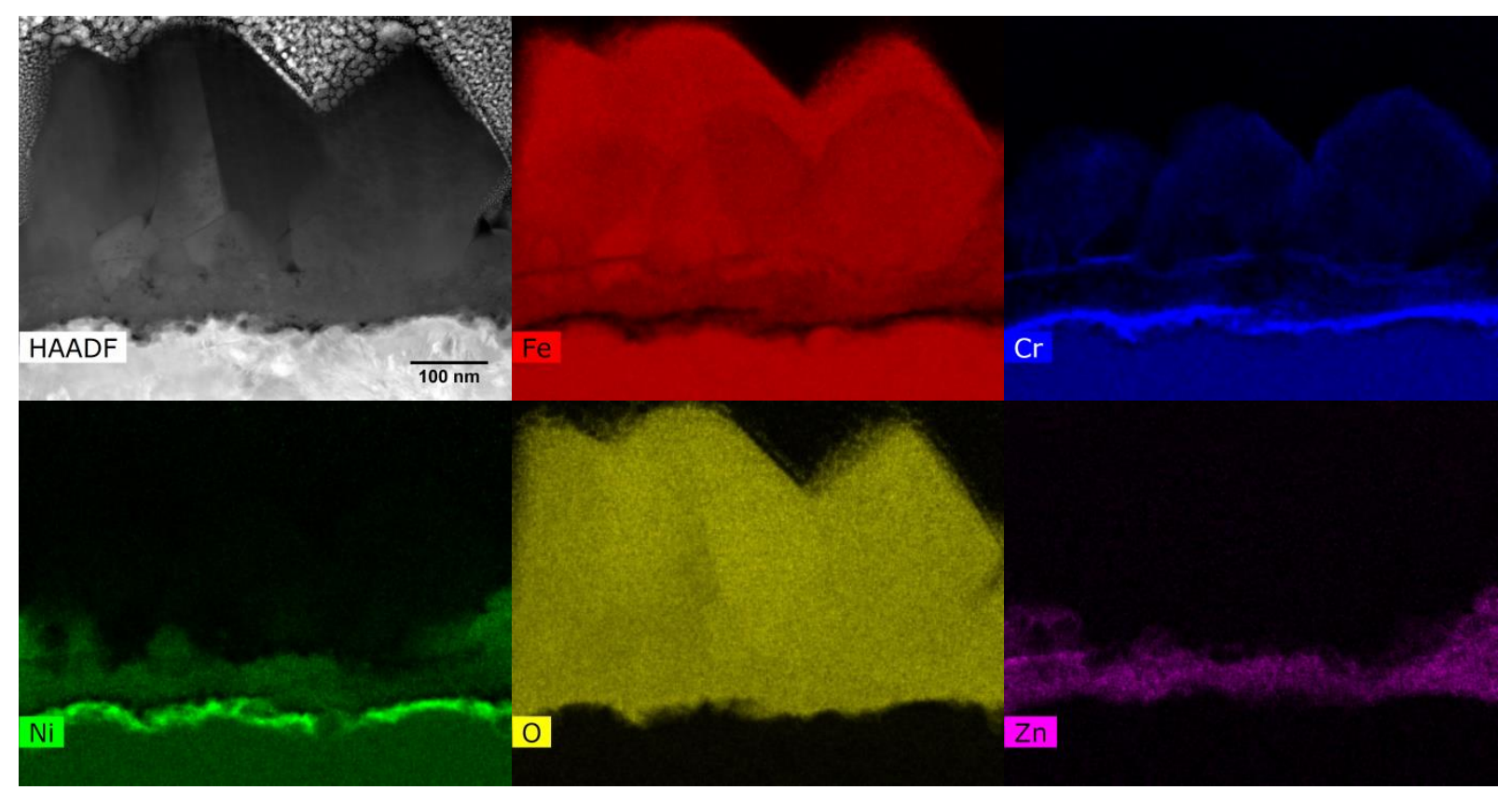

Figure 1: STEM-EDX spectrum images of the oxide formed under NWC with a 5 ppb Zn injection. Zn enrichment in the inner layer is less pronounced within the polycrystalline nickel ferrite based inner layer. 


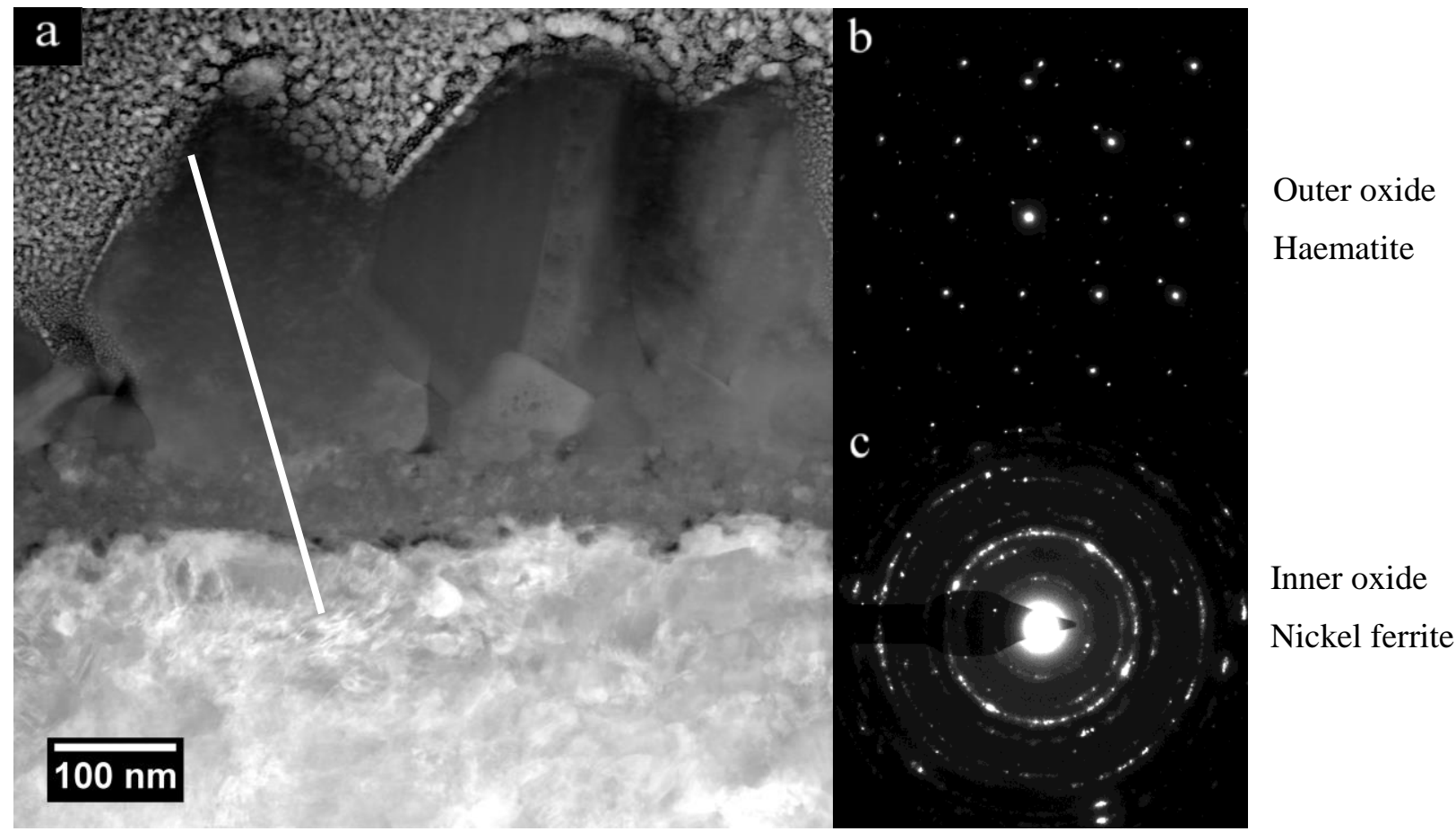

d

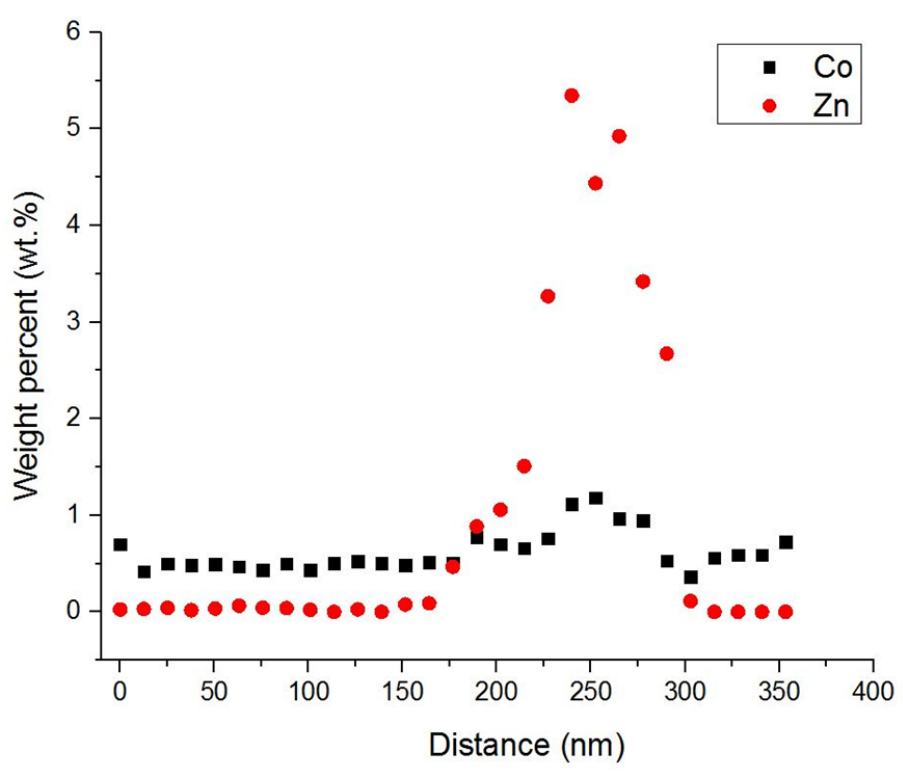

Figure 1: (a) HAADF-STEM image of the inner layer oxide with the superimposed line representing the locations of the discrete EDX spot analysis; (b) SADP of the outer oxide; (c) SADP of the inner oxide (d) Plot showing the semi quantitative $\mathrm{Co}$ and $\mathrm{Zn}$ concentration in wt. through the thickness of the oxide layer formed under NWC conditions with a 5 ppb Zn injection. 